plemented by other proceedings. The first part of the douche-massage is performed in the sitting posture, the patient sitting on a wooden stool, while both the masseurs (or masseuses) do the massage of the limbs and of the upper part of the body, all the time pouring the jet of warm water on to the part they are manipulating. The attendants are very skilful in directing the jet by the raised knee, so that both their hands are at liberty for the massage. One masseur standing behind the patient does the massage of the neck, shoulders, and upper part of the trunk, while the other standing in front massages the upper and lower limbs. The second part of the douche-massage is done with the patient in a reclining posture, lying on a wooden board put on the stool so as to make an inclined plane. While in that position it is very easy for the masseur to massage the lumbar region, the hip-joint and surrounding parts, and the sciatic nerve running along the posterior aspect of the limb, all of which require some skill and force. So much for the actual massage, the Aix. douche as it is sometimes called. After this is over the patient stands up, and while one of the attendants prepares the linen the other gives a simple douche more or less warm for one or two minutes, and in some cases in which a tonic effect is desired this final douche is war'm and cold, when it is called the Scottish douche. As to the temperature of the water in the douchemassage it may be from 90 deg. F. to 104 deg. F., or, exceptionally, to $107 \mathrm{deg}$. F.; and as to the sort of massage used, it is prescribed by the doctor, and may take the form of effleurage, pétrissage, or pressure, \&c. Its duration is ten minutes. The accessory treatment which is employed in some cases may be either (1) the general vapour bath, known as Bouillon from the bubbling noise made by the shower of hot water from which the vapour is given off. In this chamber patients may stay from three to ten minutes before or after the douche-massage, so as to get an abundant perspiration. (2) The local vapour bath, known as Berthollet, which lasts from 20 to 30 minutes, and is generally followed by a dry massage, the temperature being $100 \mathrm{deg}$. F. to 110 deg. F. (3) The ordinary tub bath. As a rule, a course of about twenty douche-massages is required, spread over about a month; but in severe cases the course lasts longer, and the tub and vapour baths are used as well as the more special douche-massage.

$$
\text { I Practitioner, May, } 1900 .
$$

\section{RUPTURE OF THE LIVER.}

guns the reports from South Africa in regard to rebouns wounds of the abdomen should lead to a injurd against operations in other cases of abdominal case of we would draw attention to a very remarkable The of extensive rupture of the liver related by Mr. result Cawardine, 1 of Bristol, in which a successful in the followed laparatomy and stuffing of the wound quarter liver with iodoform gauze, "three and threepacked yards of gauze, several folds thick," being carity into the laceration and into the abdominal by a below it. The injury was the result of a crush pulseless weight against a wall. The patient was apparent when the operation was performed, and was fluid. On kept alive by intravenous injection of saline gas or On the abdomen being opened there was no free or odour, and the spleen was intact, but the liver was found to be extensively lacerated. The right rectus was therefore cut across, and a large quantity of clot was turned out of the abdominal cavity. The whole hand could then be introduced into a laceration of the liver, which extended "right across the under surface from about the position of the gall-bladderwhich was not to be seen-to the posterior part, dividing the liver almost in twain, and leaving the upper part of the capsule floating on the blood-clot. The remainder of the right lobe appeared to be badly smashed, and could not be defined owing to its crushed condition." Yet, notwithstanding this desperate injury, the man recovered. After the operation nearly a quart of saline fluid was poured into the abdominal cavity. The patient remained pulseless for 30 hours after the operation. Two months after the injury he went to the convalescent home, from which he returned looking fat and well, with the wound securely healed. Mr. Cawardine is much to be congratulated on his success.

$$
1 \text { Lancet, May } 12 .
$$

\section{THE MALARIA PARASITE.}

$\mathrm{A}_{\mathrm{T}}$ the last meeting of the Balneological and Climatological Society, during a discussion on the climate of Rhodesia, some remarks of considerable interest were made by Dr. Alfred Hillier in regard to a point in the natural history of malaria, to which we have more than once directed attention, namely, the probability that man is not the only host of the malaria parasite from whom the mosquito can become infected. That the parasite is found in certain species of mosquito, and that it is conveyed by them to men, no reasonable student of the question can have any doubt; but when it is held, as seems to be the case by some, that the parasite can only be obtained by the mosquito from man, and can only be conveyed by the mosquito to man, Dr. Hillier thinks, and we think, that the theory goes beyond the proof, and he points to certain facts which appear to militate against it. For instance, as he says, Rhodesia is a huge country of 150,000 square miles, while its entire population is estimated at 300,000 blacks and 15,000 white. Very large portions of the country, therefore, are uninhabited, and in some of these districts - the low-lying, swampy ground, where malaria is most virulent-there is in many instances no population at all, yet parties of hunters wandering in such districts are often prostrated to a man by malaria. This being so, Dr. Hillier very properly asks, From whom can the mosquitos in these cases have derived the parasite? and confesses to considerable doubt as to whether man is the only host from whom the parasite may be derived. The question is, of course, one of the greatest possible interest on account of its practical bearing upon the measures to be taken for the prevention of the disease.

\section{A MOSQUITO-PROOF DWELLING.HOUSE.}

IT is arranged that Dr. Sambon and Dr. G. C. Low, with their servants, shali live in the most malarious part of the Roman Campagna during the worst season of this year-namely, from June till October-with the object of testing the possibility of keeping free from the disease by the simple methol of keeping within a mosquito-proof house during the hours when mosquitos bite-namely, from an hour before sunset to an hour 